\title{
Size-isolation of superparamagnetic iron oxide nanoparticles improves MRI, MPI and hyperthermia performance
}

\author{
Seyed Mohammadali Dadfar ${ }^{1}$ (D, Denise Camozzi ${ }^{2}$, Milita Darguzyte ${ }^{1}$, Karolin Roemhild ${ }^{1}$, Paola Varvarà ${ }^{3}$, \\ Josbert Metselaar', Srinivas Banala', Marcel Straub ${ }^{1}$, Nihan Güvener ${ }^{1}$, Ulrich Engelmann', Ioana Slabu', \\ Miriam Buhl', Jan van Leusen ${ }^{6}$, Paul Kögerler ${ }^{6}$, Benita Hermanns-Sachweh ${ }^{5}$, Volkmar Schulz ${ }^{1}$, Fabian Kiessling ${ }^{1}$ \\ and Twan Lammers ${ }^{1,7,8^{*}}$ (i)
}

\begin{abstract}
Superparamagnetic iron oxide nanoparticles (SPION) are extensively used for magnetic resonance imaging (MRI) and magnetic particle imaging (MPI), as well as for magnetic fluid hyperthermia (MFH). We here describe a sequential centrifugation protocol to obtain SPION with well-defined sizes from a polydisperse SPION starting formulation, synthesized using the routinely employed co-precipitation technique. Transmission electron microscopy, dynamic light scattering and nanoparticle tracking analyses show that the SPION fractions obtained upon size-isolation are well-defined and almost monodisperse. MRI, MPI and MFH analyses demonstrate improved imaging and hyperthermia performance for size-isolated SPION as compared to the polydisperse starting mixture, as well as to commercial and clinically used iron oxide nanoparticle formulations, such as Resovist ${ }^{\circledR}$ and Sinerem ${ }^{\circledR}$. The size-isolation protocol presented here may help to identify SPION with optimal properties for diagnostic, therapeutic and theranostic applications.
\end{abstract}

Keywords: Iron oxide nanoparticles, SPION, MRI, MPI, Hyperthermia

\section{Introduction}

Superparamagnetic iron oxide nanoparticles (SPION) are widely used for biomedical applications, including magnetic resonance imaging (MRI), magnetic particle imaging (MPI), magnetic fluid hyperthermia (MFH), separation of biomolecules, and targeted drug and gene delivery [1-3]. This widespread list of applications not only results from the magnetic properties of SPION, but also from the capability of synthesizing them in different sizes and shapes. For all of the above applications, SPION

*Correspondence: tlammers@ukaachen.de

${ }^{1}$ Institute for Experimental Molecular Imaging, Faculty of Medicine, RWTH Aachen University, Forckenbeckstr. 55, 52074 Aachen, Germany

Full list of author information is available at the end of the article should ideally have a high magnetization value, a size below $100 \mathrm{~nm}$ and a narrow size distribution $[4,5]$.

SPION are typically based on $\mathrm{Fe}_{3} \mathrm{O}_{4}$ and/or $\mathrm{Fe}_{2} \mathrm{O}_{3}$. They can be synthesized using various methods, such as coprecipitation [5, 6], thermal decomposition [7], sol-gel [8], microemulsion [9], hydrothermal [10], and electrochemical synthesis [11]. The co-precipitation technique is among the most successful, most commonly employed and most cost-effective methods for high-yield synthesis. However, strategies are needed to overcome the most important limitation of this method, i.e. the very broad particle size distribution of the resulting SPION mixture $[5,6]$.

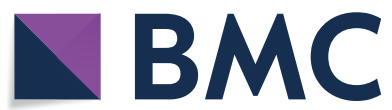

c The Author(s) 2020. This article is licensed under a Creative Commons Attribution 4.0 International License, which permits use, sharing, adaptation, distribution and reproduction in any medium or format, as long as you give appropriate credit to the original author(s) and the source, provide a link to the Creative Commons licence, and indicate if changes were made. The images or other third party material in this article are included in the article's Creative Commons licence, unless indicated otherwise in a credit line to the material. If material is not included in the article's Creative Commons licence and your intended use is not permitted by statutory regulation or exceeds the permitted use, you will need to obtain permission directly from the copyright holder. To view a copy of this licence, visit http://creativeco mmons.org/licenses/by/4.0/. The Creative Commons Public Domain Dedication waiver (http://creativecommons.org/publicdomain/ zero/1.0/) applies to the data made available in this article, unless otherwise stated in a credit line to the data. 
In this study, we describe a straightforward, easily implementable and broadly applicable centrifugation protocol to obtain relatively monodisperse SPION from a polydisperse starting mixture prepared using the co-precipitation technique. As a result of their refined size distribution, the obtained optimized SPION dispersions showed substantially improved performance in MRI, MPI and MFH compared to the crude starting formulation, as well as to commercial SPION products, such as Resovist ${ }^{\circledR}$ and Sinerem ${ }^{\circledR}$.

In this context, it is important to keep in mind that not the centrifugation protocol per se, but the eventual development of a SPION formulation with a very welldefined size and with a very narrow size distribution (and its consequent more optimal use for diagnostic and therapeutic purposes) is the objective of our work. Thus far, no systematic study has been published on SPION size-isolation via sequential centrifugation, and no systematic analysis is available in which the performance of five size-isolated SPION sub-fractions (and clinically/commercially relevant controls) is head-tohead compared in MRI, MPI and MFH setups.

\section{Results and discussion} SPION preparation and size-isolation

Prototypic citrate-coated SPION were prepared via the standard co-precipitation technique, under nitrogen atmosphere [5, 6] (see "Experimental" section for details). Based on this highly polydisperse starting batch, which we refer to as the "crude sample", five sequential rounds of centrifugation were performed to obtain much more monodispersed SPION subfractions. To this end, as depicted schematically in Fig. 1, the crude sample was transferred into $1.5 \mathrm{ml}$ Eppendorf tubes and centrifuged at $14,000 \mathrm{rpm}$ for $20 \mathrm{~min}$. The resulting $1 \mathrm{ml}$ of supernatant was collected and referred to as the "C1 sample". Subsequently, $0.1 \mathrm{ml}$ of the bottom compartment in the Eppendorf tube that contained the largest nanoparticle fraction was resuspended in water. The obtained dispersion was then again centrifuged, the top $1 \mathrm{ml}$ was collected as the "C2 sample", and the bottom $0.1 \mathrm{ml}$ was again resuspended and re-centrifuged. These steps were sequentially repeated to obtain five fractions of relatively monodisperse SPION samples. These fractions are referred to as $\mathrm{C} 1-\mathrm{C} 5$. The crude starting mixture,

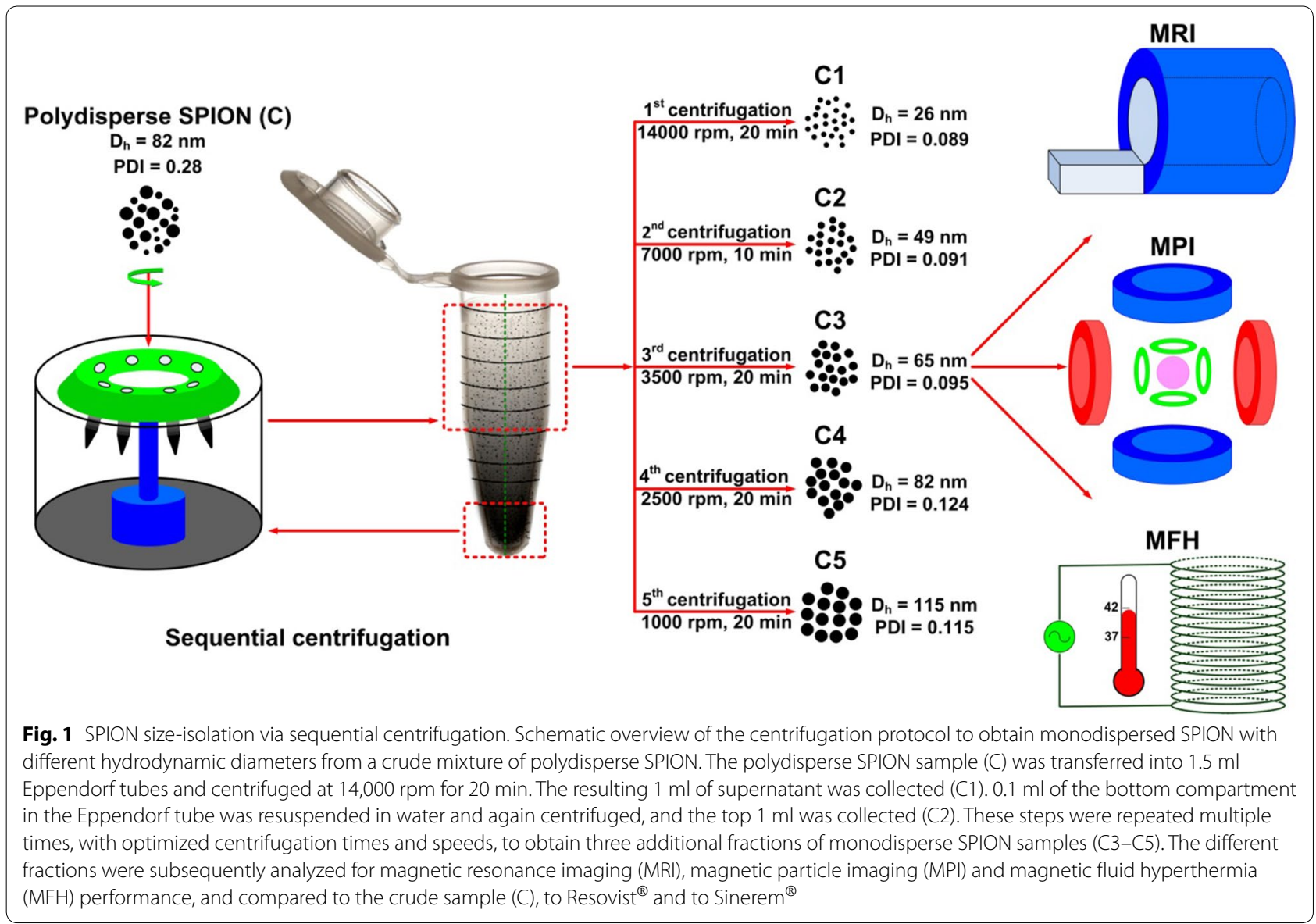


Resovist $^{\circledR}$ and Sinerem ${ }^{\circledR}$ are referred to as $C, R$ and $S$, respectively. Multiple systematic experiments were performed to identify the optimal centrifugation speeds and times for obtaining monodispersed SPION with welldefined sizes. The optimum conditions for size-isolation are presented in Fig. 1. The production efficiencies of the size-isolated fractions $\mathrm{C} 1, \mathrm{C} 2, \mathrm{C} 3, \mathrm{C} 4$ and $\mathrm{C} 5$ were approximately $7,29,23,18$ and $11 \%$, respectively.

Despite the large number of previous publications describing the synthesis of iron oxide nanoparticles, the tools and technologies for their size separation are relatively limited. Techniques employed to control average particle size and polydispersity can be based on the use of magnetic/electric fields, porous media, and mass- and density-based purification [12-14]. Fortin and colleagues for instance synthesized citrate-coated nanocrystals of maghemite and cobalt ferrite by alkaline co-precipitation, and size-sorted the nanoparticles by successive electrostatic phase separation [15]. Magnetic field-flow fractionation (MFFF) uses a homogeneous external magnetic field applied orthogonal to the direction of flow, to achieve efficient separation of particles [12]. Nonmagnetic size-exclusion chromatography (SEC) is another frequently used method for size separation of iron oxide nanoparticles. The fractions separated by SEC and MFFF have similar size distributions. However, MFFF is faster and has a higher capacity $[12,16]$. In addition to the above techniques, differential magnetic catch-and-release (DMCR) has recently been established to size-sort magnetic nanoparticles. DMCR, like MFFF, relies on an external magnetic field to separate magnetic species [17]. High-gradient magnetic separation (HGMS) is a column flow method used to isolate iron oxide nanoparticles from a nonmagnetic medium [18]. Capillary electrophoresis (CE) is used for the separation of colloidal nanoparticles in an electric field. CE requires specialized equipment, because of the high electric field. Electrical field-flow fractionation (EIFFF) separates iron oxide nanoparticles based on their size and electrophoretic mobility but without the drawbacks of CE $[12,16]$. As compared to the above techniques, the here presented centrifugation method is somewhat more time- and labor-intensive, but it is also easier to perform and more broadly applicable, because it does not require specialized equipment.

\section{Particle size, size distribution and surface charge}

Figure 2 shows the results obtained using TEM, DLS and NTA on the size and size distribution of the SPION formulations prepared and evaluated in this study. The reported TEM values which correspond to the average size were calculated on the basis of manually measuring at least 100 randomly chosen particles, using Image SP Viewer software. The average core sizes of the samples $\mathrm{C} 1, \mathrm{C} 2, \mathrm{C} 3, \mathrm{C} 4$ and $\mathrm{C} 5$ were $7.7 \pm 1.6,10.6 \pm 1.8$, $13.1 \pm 2.2,15.6 \pm 2.8$ and $17.2 \pm 2.1 \mathrm{~nm}$, respectively (Fig. 2a, b). This indicates that all five fractions are superparamagnetic, as SPION typically present superparamagnetic behavior when their core size is below $20 \mathrm{~nm}$ [5]. The corresponding average hydrodynamic diameters obtained by DLS-based on intensity-for the five samples were $26.3 \pm 1.2,49.4 \pm 1.1,64.8 \pm 2.1$, $82.1 \pm 2.3$ and $114.6 \pm 4.4 \mathrm{~nm}$ (Fig. 2c). The average sizes obtained using NTA were comparable to the values observed in DLS (Fig. 2d). The numerical values corresponding to the results presented in Fig. $2 \mathrm{~b}-\mathrm{d}$ are provided in Additional file 1: Table S1. The fact that the TEM sizes are smaller than those obtained via DLS and NTA can be explained by keeping in mind that DLS and NTA measure the hydrodynamic diameter of the citrate-coated SPION in aqueous solution incorporating surface-bound water layers in their measurement, while TEM determines the actual core size of dried nanoparticle formulations.

The results obtained using DLS, NTA and TEM demonstrate that both the core size and the hydrodynamic diameter gradually increase upon employing our centrifugation protocol. In this regard, it is important to note that from $\mathrm{C} 1$ to $\mathrm{C} 5$, the increase in hydrodynamic diameter (DLS) is much larger than the increase in core size (TEM). Equally important is the notion that the polydispersity indices (PDI) obtained from DLS confirmed that the samples $\mathrm{C} 1-\mathrm{C} 5$ have a much narrower size distribution than the crude sample, and also than Resovist ${ }^{\circledR}$ and Sinerem ${ }^{\circledR}$. The PDI for the crude sample, for Resovist ${ }^{\circledR}$ and for Sinerem ${ }^{\circledR}$ were $0.28 \pm 0.04$, $0.26 \pm 0.05$ and $0.20 \pm 0.04$, respectively, while for $\mathrm{C} 1-$ C5, all PDI's were approximately 0.10 (Fig. 2e). The size distribution results obtained by TEM are in good agreement with this (see the insets in Fig. 2a and the data presented in Fig. 2e). Based on these results, it is concluded that our sequential centrifugation protocol is highly useful for achieving relatively monodisperse SPION formulations. Consequently, it is considered to be a useful alternative to more complex synthetic methods to obtain relatively uniform SPION, such as thermal decomposition, which requires very high temperatures and which critically depends on efficient and tailored means for surface modification to eventually obtain water-dispersible SPION formulations [7].

We also determined the zeta potential for the differently sized iron oxide nanoparticle samples (Additional file 1: Figure S1). The results confirm the expected highly negatively surface charge for all size-isolated 


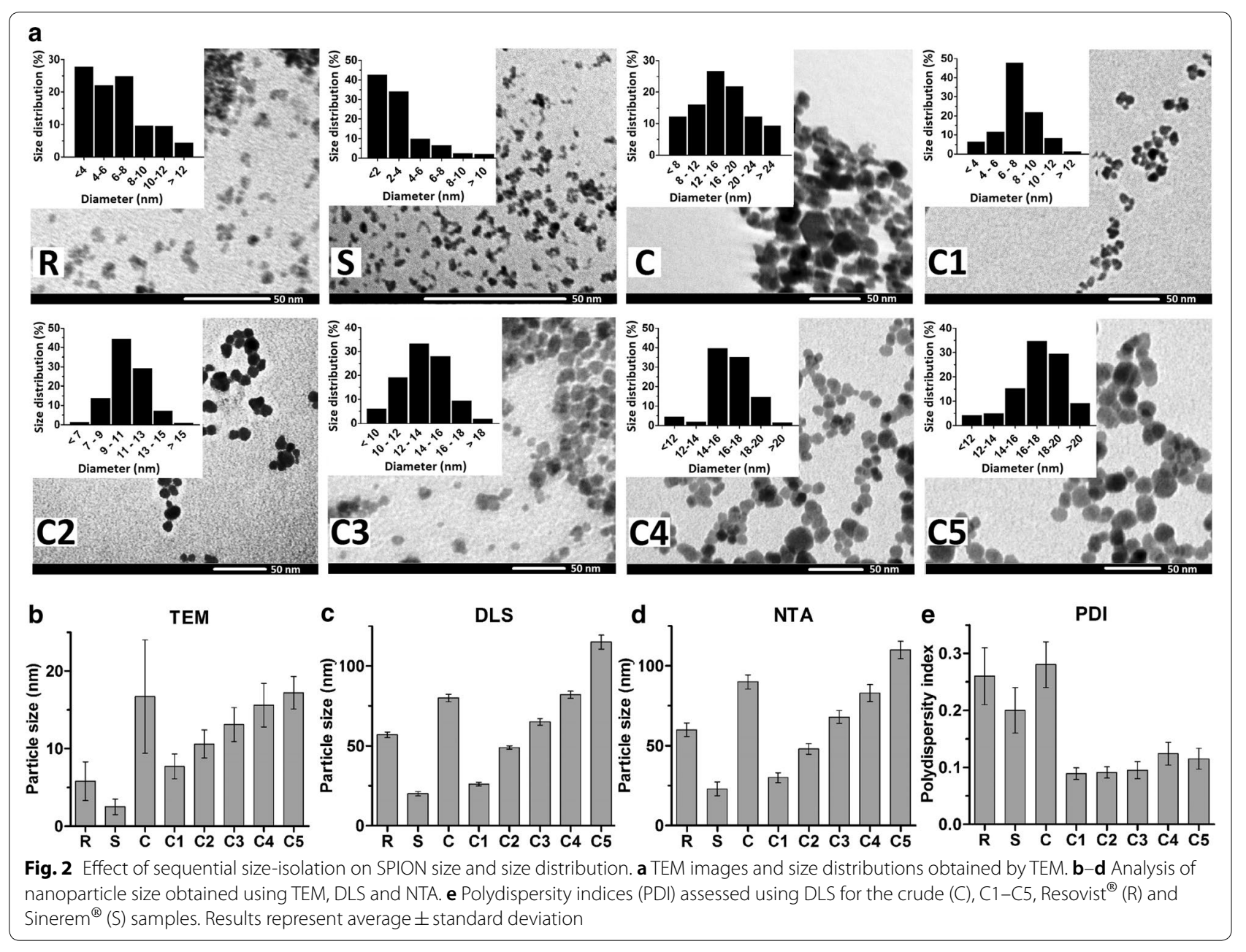

fractions $(\mathrm{C} 1-\mathrm{C} 5)$, which contributes to their high colloidal stability.

\section{SPION biocompatibility}

Almost all SPION formulations were found to be biocompatible. Additional file 1: Figures S2-S4 document the observed cytotoxicity for the crude, $\mathrm{C} 1-\mathrm{C} 5$, Resovist $^{\circledR}$ and Sinerem ${ }^{\circledR}$ samples studied by XTT, LDH and ROS assays. XTT analysis at iron concentrations of 0.1 and $1.0 \mathrm{mM}$ showed no significant differences in the viability of NIH3T3 cells upon incubation with the samples C1-C5 as compared to Resovist ${ }^{\circledR}$ and Sinerem ${ }^{\circledR}$. Interestingly, at iron concentrations of 5 and $10 \mathrm{mM}$, XTT-based viability assessment indicated that all monodispersed samples except for $\mathrm{C} 1 \mathrm{had}$ an even higher biocompatibility than Resovist ${ }^{\circledR}$ and Sinerem ${ }^{\circledR}$ (Additional file 1: Figure S2). The XTT findings were confirmed using the LDH assay (Additional file 1: Figure S3). At iron concentrations of 0.1 and $1 \mathrm{mM}$, no changes in NIH3T3 membrane damage were noted for C1-C5 as compared to Resovist ${ }^{\circledR}$ and Sinerem ${ }^{\circledR}$, while at iron concentrations of 5 and $10 \mathrm{mM}$,
LDH values (and membrane damage) were lower than for Resovist ${ }^{\circledR}$ and Sinerem ${ }^{\circledR}$ (again except for the smallestsized batch $\mathrm{C} 1$ ). In line with this, analysis of ROS production in NIH3T3 cells showed that there was no significant change in the ROS content of cells exposed to the monodispersed samples $\mathrm{C} 1-\mathrm{C} 5$ as compared to the crude sample, Resovist ${ }^{\circledR}$ and Sinerem ${ }^{\circledR}$ (Additional file 1: Figure S4). Together, these results demonstrate that all monodispersed samples except for $\mathrm{C} 1$ have negligible toxicity. The higher cytotoxicity associated with the smallest particles is assumed to result from a more rapid and more extensive cellular uptake, as well as from a relatively larger surface area [19-21].

\section{SPION stability in physiological media}

All size-isolated SPION samples showed excellent stability in DI water (see columns 4 and 5 of Additional file 1: Table S1; demonstrating stable dispersion up to 6 months). This can be attributed to the highly negatively charged surface of the SPION. All SPION formulations also showed high colloidal stability in physiological 
media, i.e. in fetal bovine serum (FBS) and in bovine serum albumin (BSA). The monitoring of the samples by visual inspection up to $24 \mathrm{~h}$ implied the absence of aggregation of SPION (see Additional file 1: Figures S5a and S6a). In line with this, the hydrodynamic diameters and PDI obtained using DLS for 2, 6 and $24 \mathrm{~h}$ of incubation in physiological media did not show significant changes in size and size distribution (see Additional file 1: Figures S5b, c, S6b, c and Table S1). In good agreement with our findings, $\mathrm{Yu}$ et al. synthesized two different types of SPION with different surface coatings: tetramethylammonium hydroxide-coated SPION (T-SPION) and citrate-coated SPION (C-SPION). The C-SPION showed robust stability in biological media, while T-SPION aggregated rapidly in all media evaluated [22].

\section{Magnetic properties}

Field-dependent magnetization analysis of the $\mathrm{C} 1-\mathrm{C} 5$ samples showed no discernible hysteresis, demonstrating that they are superparamagnetic (Fig. 3a). For biomedical applications, iron oxide nanoparticles with superparamagnetic behavior are preferred, because in case of superparamagnetic materials, the magnetization drops to zero after removing the applied magnetic field. This implies that due to lack of coercive forces or remanence, it keeps the nanoparticles from sticking together, avoiding aggregation and the formation of clots in the blood stream, which could lead to serious adverse events [23].

The saturation magnetizations $\left(M_{s}\right)$ of samples were very high, indicating an excellent magnetic response to the magnetic field (Fig. 3b). Three important observations were obtained by these analyses: first, comparing the $\mathrm{M}_{\mathrm{s}}$ values of the samples $\mathrm{C} 2$ and $\mathrm{C} 3$ at $5 \mathrm{~K}$ and 30 $\mathrm{kOe}$ (73.8 and $82.5 \mathrm{emu} / \mathrm{g}$, respectively) to those of Resovist $^{\circledR}$ and Sinerem ${ }^{\circledR}$ (53.1 and $28.8 \mathrm{emu} / \mathrm{g}$, respectively) illustrates the good magnetic properties of $\mathrm{C} 2$ and $\mathrm{C} 3$. Second, the $\mathrm{M}_{\mathrm{s}}$ values for $\mathrm{C} 2$ and $\mathrm{C} 3$ are approximately three-quarters of the $M_{s}$ value of bulk magnetite, which is $\sim 100 \mathrm{emu} / \mathrm{g}$ at $5 \mathrm{~K}$ and $30 \mathrm{kOe}$ [24]. Third, the magnetization reaches $94 \%$ of its maximum value for $\mathrm{C} 2$ and $93 \%$ of its maximum value for $\mathrm{C} 3$ in magnetic fields as low as $5 \mathrm{kOe}$, underlining the suitability of these samples for the envisaged applications. Field-cooled (FC) magnetization measurements were also carried out, in an applied field of $1000 \mathrm{Oe}$, at temperatures ranging from 5 to $300 \mathrm{~K}$. As shown in Additional file 1: Figure S7, the FC curves demonstrate only a very little decrease with temperature for all nanoparticle samples tested, and the results obtained are in good agreement with those of saturation magnetization analyses.

Both MRI and MPI rely on the use of magnetic nanoparticles with strong saturation magnetization, high magnetic susceptibility and no coercivity. Similarly, also for $\mathrm{MFH}$, the amount of saturation magnetization should be as high as possible, to guarantee efficient heating under an alternating magnetic field [23]. Saturation magnetization of SPION depends not only on core size, but also on other parameters, such as size distribution, type of coating, chemical composition (with magnetite being better than maghemite) and crystalline structure. Generally, a larger particle size results in higher saturation magnetization values and in a better performance in MRI, MPI and MFH. However, when the particle size is too large, magnetic nanoparticles become ferromagnetic and the

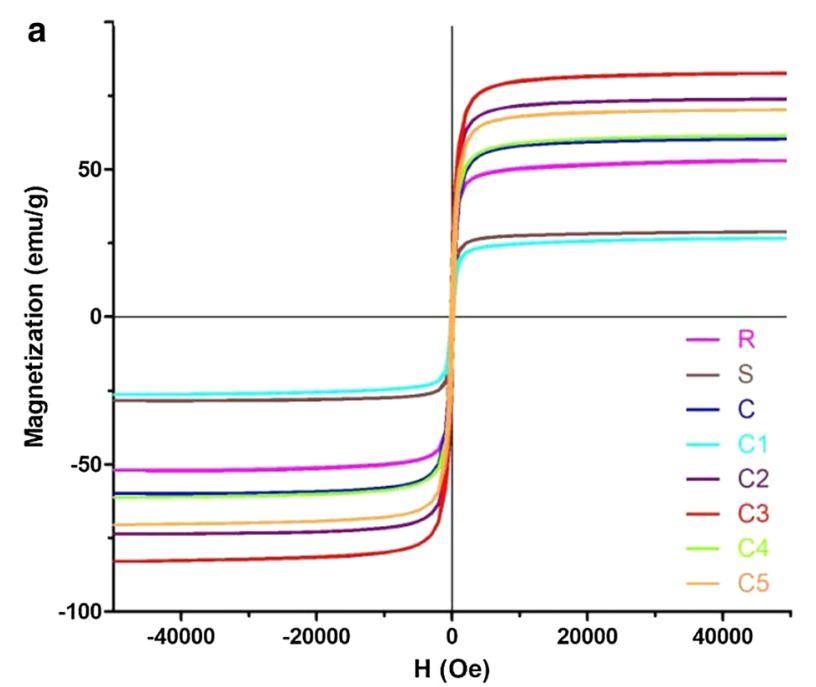

b

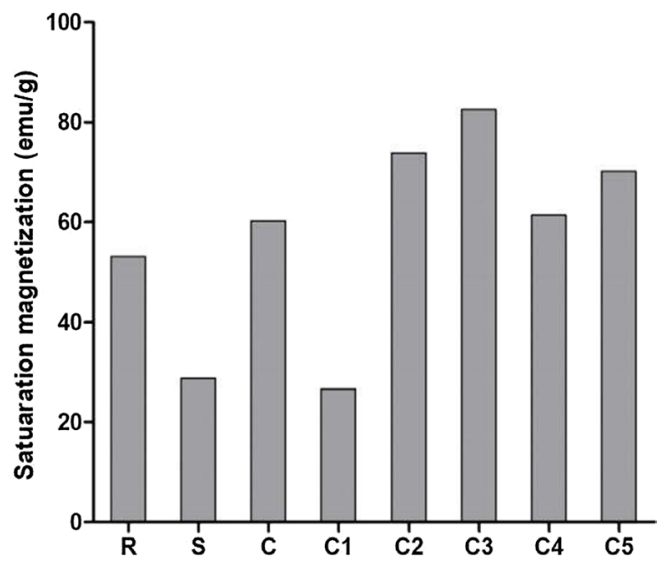

Fig. 3 Magnetic characterization. a Field-dependent magnetization at 5 K. b Saturation magnetization at 5 K of the crude SPION mixture (C), the size-isolated samples C1-C5, Resovist ${ }^{\circledR}(\mathrm{R})$ and Sinerem ${ }^{\circledR}(\mathrm{S})$. Results were normalized to Fe content 
saturation magnetization drops, which is undesired for biomedical applications. For the $\mathrm{C} 1-\mathrm{C} 5$ samples, fielddependent magnetization analysis revealed that all fractions are in the superparamagnetic range. Increasing the size gradually approaches ferromagnetic behavior, explaining the somewhat lower saturation magnetization values for $\mathrm{C} 4$ and $\mathrm{C} 5$ as compared to $\mathrm{C} 2$ and $\mathrm{C} 3$. Also, the low saturation magnetization for $\mathrm{C} 4$ and $\mathrm{C} 5$ compared to $\mathrm{C} 2$ and $\mathrm{C} 3$ could be explained on the basis of a more polycrystalline structure of the samples. Conversely, it is important to keep in mind that smaller-sized nanoparticles are typically preferred in vivo, e.g. because they can more readily exploit vascular leakiness in tumors and at sites of inflammation, and because they allow for deeper target tissue penetration. These considerations exemplify that it is crucial to identify the optimal size for the anticipated biomedical application $[25,26]$, and they underline the importance of developing tools, such as the centrifugation protocol presented here, to prepare SPION formulations with distinct sizes and with low polydispersity.

Another important thing to keep in mind is that sometimes the saturation magnetization is found to be lower than expected. This reduction in magnetic performance of the nanoparticles can be attributed to the existence of a "magnetically dead layer" on their surfaces. Because of this magnetically dead layer, the magnetic diameter is smaller than the physical diameter, sometimes by several nanometers. Saturation magnetization is proportional to the magnetic diameter, not physical diameter [27-29]. As an example to illustrate this, Unni and colleagues synthesized two series of iron oxide nanoparticles with a similar diameter of $21 \mathrm{~nm}$ via thermal decomposition; the MS value was $17 \mathrm{emu} / \mathrm{g}$ for one nanoparticle, and $74 \mathrm{emu} / \mathrm{g}$ for the other [27]. Kemp et al. produced monodisperse magnetite nanoparticles with diameters in the range between 15 and $30 \mathrm{~nm}$ by thermolysis and they varied oleic acid ratios for size control. With increasing particle size, there was no clear trend in saturation magnetization (sometimes increasing and sometimes decreasing) [28]. Such irregularities were also observed by Baaziz et al. for iron oxide nanoparticles with diameters between 4 and $28 \mathrm{~nm}$ [29]. The lower MS values for the samples C4 and $\mathrm{C} 5$ as compared to $\mathrm{C} 2$ and $\mathrm{C} 3$ can be explained by taking the above notions into account.

\section{Magnetic resonance imaging}

All SPION samples showed excellent performance as contrast agent for magnetic resonance imaging (MRI). Figure 4 and Additional file 1: Figures $S 8-10$ show $T_{1}$ and $\mathrm{T}_{2}$-weighted $\mathrm{MR}$ images and quantification of key MRI parameters for the crude, C1-C5, Resovist ${ }^{\circledR}$ and Sinerem ${ }^{\circledR}$ samples [i.e. relaxivities $\left(r_{1}, r_{2}\right)$, relaxation rates $\left(1 / \mathrm{T}_{1}, 1 / \mathrm{T}_{2}\right)$ and relaxivity ratios $\left.\left(\mathrm{r}_{2} / \mathrm{r}_{1}\right)\right]$. Figure 4 indicates that all newly prepared samples, i.e. both the monodisperse and the polydisperse SPION, have transverse relaxivities $\left(\mathrm{r}_{2}\right)$ greater than Resovist ${ }^{\circledR}$ and Sinerem ${ }^{\circledR}$. Interestingly, while the crude starting mixture and Resovist ${ }^{\circledR}$ were both highly polydisperse, the $r_{2}$ value of the former was found to be two times higher than that of the latter.

After sequential centrifugation, the $r_{2}$ values of the monodisperse SPION gradually increased up until the third round of centrifugation. The $\mathrm{C} 3$ sample with $13.1 \pm 2.2 \mathrm{~nm}$ core size possessed the most optimal MRI
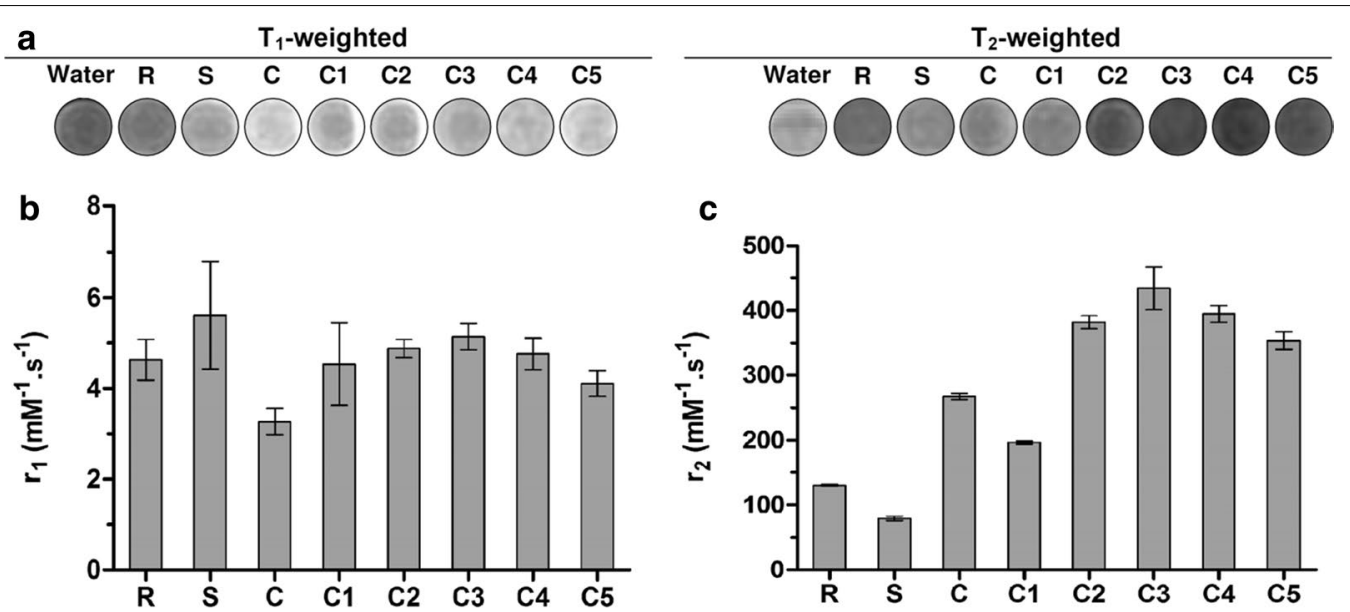

Fig. 4 Magnetic resonance imaging of size-isolated SPION. MRI of the crude, C1-C5, Resovist ${ }^{\circledR}$ and Sinerem ${ }^{\circledR}$ samples upon characterization on a $3 \mathrm{~T}$ clinical scanner. $\mathbf{a} \mathrm{T}_{1}$ - and $\mathrm{T}_{2}$-weighted $\mathrm{MR}$ images of the samples at a concentration of $0.01 \mathrm{mM}$. MR images for other SPION concentrations are provided in Additional file 1: Figure S8. $\mathbf{b}$ and $\mathbf{c}$ Longitudinal $\left(r_{1}\right)$ and transversal $\left(r_{2}\right)$ relaxivities of the samples in water. Values represent average \pm standard deviation of three independent samples 
capabilities, with an $\mathrm{r}_{2}$ value of $434 \mathrm{mM}^{-1} \mathrm{~s}^{-1}$. It produced 3.3 and 5.5 times more contrast in $\mathrm{T}_{2}$-weighted imaging than Resovist ${ }^{\circledR}\left(130 \mathrm{mM}^{-1} \mathrm{~s}^{-1}\right)$ and Sinerem ${ }^{\circledR}$ $\left(79 \mathrm{mM}^{-1} \mathrm{~s}^{-1}\right)$, respectively. A number of studies have demonstrated that the core size, the size distribution and the magnetization of SPION are key factors influencing the transverse relaxation rate $\left(1 / \mathrm{T}_{2}\right)[15,30]$. The trend for the $r_{1}$ values for the samples $\mathrm{C} 1-\mathrm{C} 5$ was found to be similar to that observed for the $r_{2}$ values.

The efficiency of a T2 contrast agent relies on the r2/ $\mathrm{r} 1$ ratio in addition to the $\mathrm{r} 2$ value [31]. In this context, it is important to note that for all size-isolated samples, it can be concluded that there is a specific enhancement of the $r_{2} / r_{1}$ ratio in comparison to Resovist ${ }^{\circledR}$ and Sinerem ${ }^{\circledR}$ (Additional file 1: Figure S10), confirming the suitability of these samples for $\mathrm{T}_{2}$-weighted MR imaging.

Saraswathy and colleagues synthesized citrate-coated iron oxide nanoparticles with a similar coating and with a similar core size as C3 sample. They employed this SPION formulation for in vivo magnetic resonance imaging of liver fibrosis. The values for $r_{1}$ and $r_{2}$ were 2.69 and $102 \mathrm{mM}^{-1} \mathrm{~s}^{-1}$, respectively [32]. Comparing the $r_{2} / r_{1}$ value of their formulation (i.e. 37.9$)$ to that of our C3 sample (i.e. 84.4) exemplifies the usefulness and the potential added value of our sequential size-isolation protocol. Smolensky et al. investigated the effect of multiple parameters, including particle size and shape, temperature and magnetic field strength, on the longitudinal and transverse relaxivities of iron oxide nanoparticles. According to their findings, $r_{2}$ values increased linearly with increasing core size (from 4.9 to $18 \mathrm{~nm}$ ), while $r_{1}$ values remained relatively constant for particles with core sizes larger than $8 \mathrm{~nm}$ [33]. Surface coating and nanoparticle aggregation are also highly important parameters. Blanco-Andujar and coworkers studied the evolution of $r_{2}$ with SPION aggregate size [34]. In case of small clusters, nanoparticles are homogeneously dispersed in water and protons can readily diffuse between the magnetic cores. Under these conditions, $r_{2}$ values gradually increase with hydrodynamic diameter (up to approx. $80 \mathrm{~nm}$ ). At a size of $80-90 \mathrm{~nm}$, there is no further increase in $r_{2}$. If the size exceeds $90 \mathrm{~nm}, \mathrm{r}_{2}$ values start to decrease with increasing size, due to reductions in surface accessibility and proton exchange rate. This trend is in line with our results, showing reductions in $r_{2}$ values when the hydrodynamic diameter goes beyond $70 \mathrm{~nm}\left(\mathrm{r}_{2}\right.$ values for $\mathrm{C} 4$ and $\mathrm{C} 5$ are 398 and $350 \mathrm{mM}^{-1} \mathrm{~s}^{-1}$, respectively, as compared to $434 \mathrm{mM}^{-1} \mathrm{~s}^{-1}$ for $\mathrm{C} 3$ ).

\section{Magnetic particle imaging}

SPION are important tracer materials for magnetic particle imaging (MPI). MPI is a novel and increasingly popular hot-spot imaging technique that can be employed to visualize magnetic nanoparticles with very high temporal and spatial resolution. MPI is able to provide realtime 3D imaging information on the localization and concentration of magnetic nanoparticles, and it can be employed for multiple medical imaging applications [35]. The potential usefulness of MPI strongly depends on the availability of size-optimized SPION to generate high quality images. As a matter of fact, MPI contrast generation critically depends on both SPION size and size distribution, since both parameters strongly affect the magnetization response.

Resovist $^{\circledR}$ was originally developed as a contrast agent for MRI. In recent years, it has also been extensively employed for MPI, because of its large magnetic moment. At the moment, Resovist ${ }^{\circledR}$ is the most extensively employed SPION formulation for MPI. From TEM images, it is known that Resovist ${ }^{\circledR}$ mainly consists of particles with an average core diameter of $5.8 \pm 2.5 \mathrm{~nm}$, many of which are agglomerated in clusters (Fig. 2a). It is assumed that these aggregates, which are formed by small elementary particles, are responsible for its good MPI performance [26]. However, the MPI performance of Resovist ${ }^{\circledR}$ still leaves significant room for improvement. As result of this, in recent years, ever more scientists have started to work on the development of better SPION formulations for MPI [26, 36].

Figure 5a shows the MPI signal-to-noise (SNR) values of the different SPION formulations used in this study, obtained at the 4th harmonic frequency of the drive field. It also shows the full width at half maximum (FWHM) values, and the hysteresis loss determined from the point spread function (PSF) measurements. To allow for a quantitative comparison, it is generally considered to be sufficient to read the SNR at one harmonic frequency. This is typically the 4th harmonic frequency (Fig. 5a). Additional file 1: Figure S11 shows the SNR values for other harmonic frequencies. To compare the MPI performance of the different samples, SNR values were normalized to the iron concentration inside the probe volume. The normalized SNR values for C2 and C3 were found to be much higher than for all other samples. At the 4th harmonic frequency, the normalized SNR for C2 was 2.3 and 7.0 times higher than for Resovist ${ }^{\circledR}$ and Sinerem ${ }^{\circledR}$, respectively. In addition, FWHM and hysteresis loss analysis showed that $\mathrm{C} 2$ and $\mathrm{C} 3$ were almost as good as Resovist $^{\circledR}$. Lower FWHM and hysteresis loss values refer to a higher achievable spatial resolution and to a lower spatial displacement in MPI, respectively.

To exemplify the MPI imaging capabilities of our sizeisolated SPION, we fabricated two phantoms. One was an E-shaped phantom (Fig. 5b), serving as a somewhat more complex structure, made up of single tracer-filled dots of $0.5 \mathrm{~mm}$. The other phantom was V-shaped (Additional 

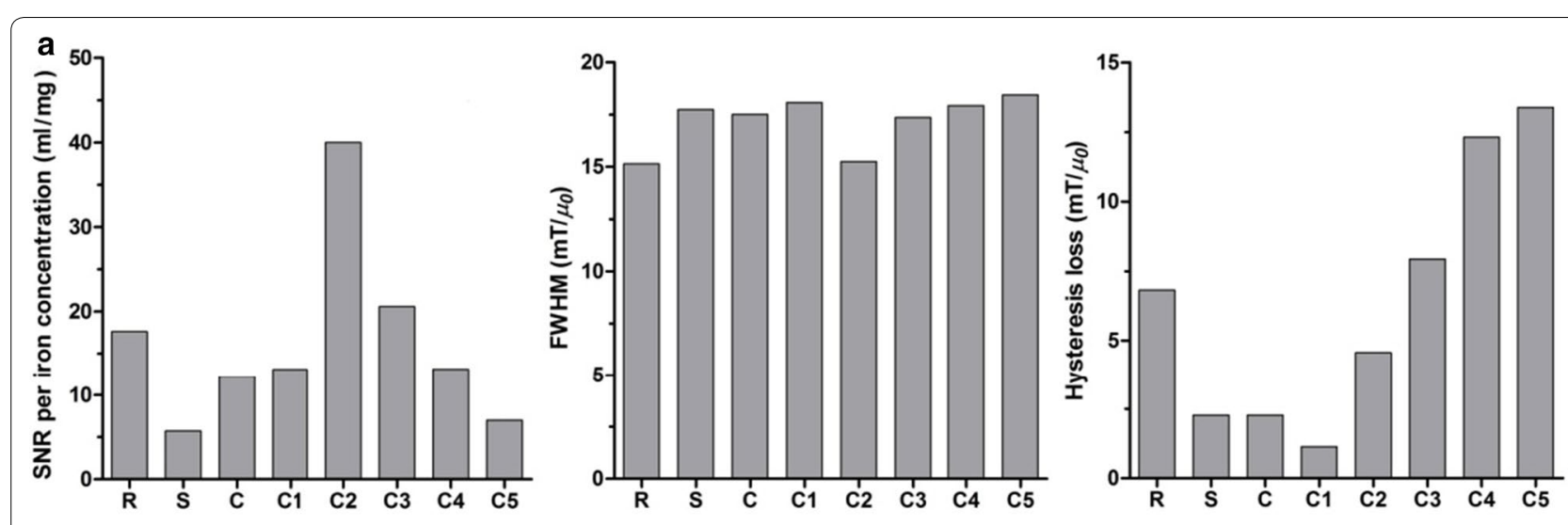

b
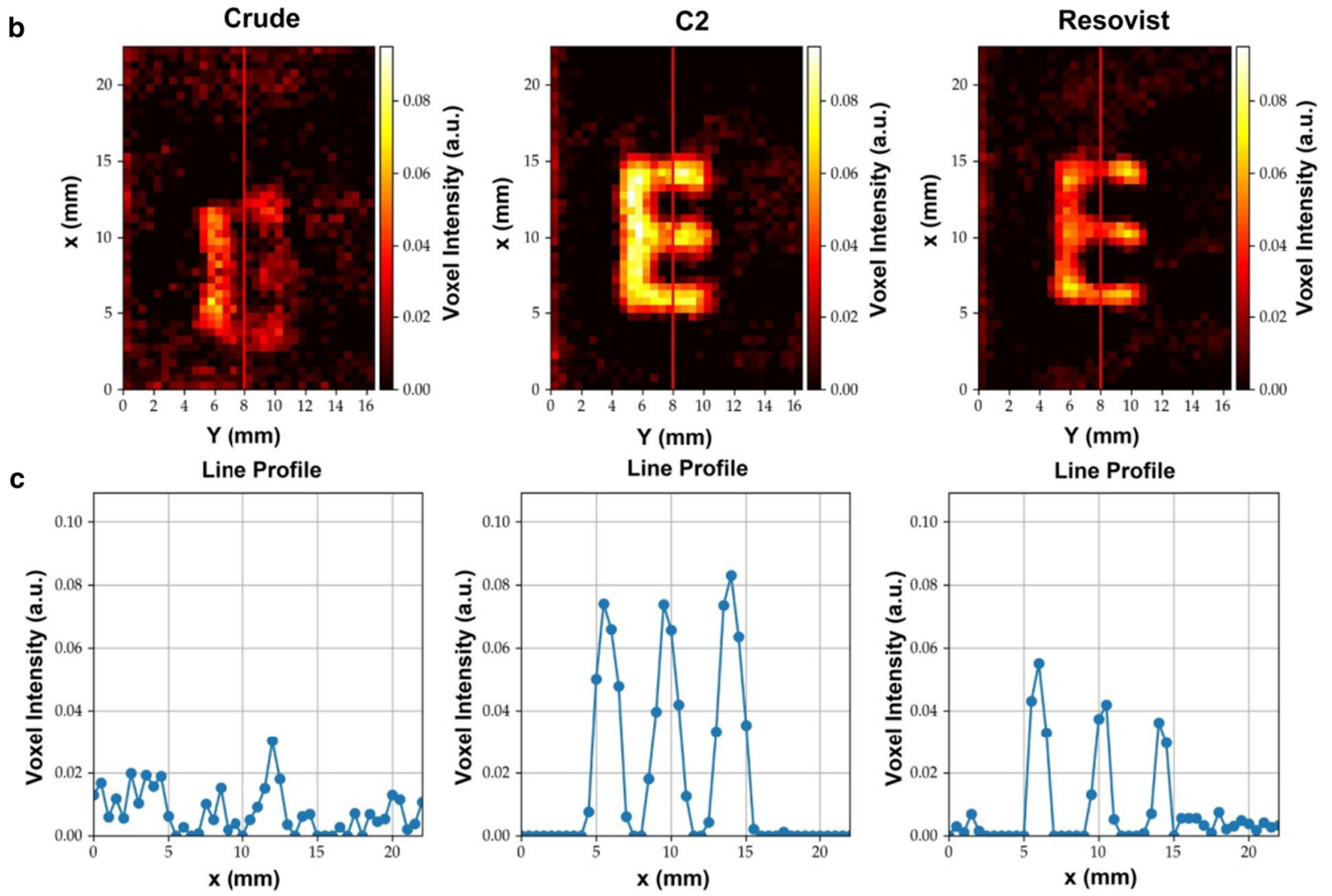

Fig. 5 Magnetic particle imaging of size-isolated SPION. a Key MPI parameters including normalized signal-to-noise ratios (SNR) of the samples at the 4th harmonic of the MPI drive field as well as full width at half maximum (FWHM) measurements and hysteresis loss analyses of the samples were obtained using magnetic particle spectroscopy (MPS; which is comparable to a zero-dimensional MPI acquisition without the superimposed gradient field measurements). b MPI images reconstructed based on "E" shaped phantoms filled with the crude sample, $C 2$ and Resovist ${ }^{\circledR}$. $\mathbf{c}$ The intensity line profiles of the red marked lines through the phantoms in $\mathbf{b}$ are shown. The line profiles show the voxel intensity along the marked line and demonstrate a doubling of signal intensity for C2 in comparison to Resovist ${ }^{\circledR}$

file 1: Figure S12a), and consisted of single dots with a diameter of $0.5 \mathrm{~mm}$ with an increasing distance between them $(2,3,4,5$ and $6 \mathrm{~mm})$. Both phantoms were filled with the crude starting mixture, with the $\mathrm{C} 2$ sample and with Resovist ${ }^{\circledR}$, making sure that the iron concentrations were identical. Figure $5 \mathrm{c}$ and Additional file 1: Figure
S12b show the line profiles of the voxel intensities along the red marked lines for the $\mathrm{E}$ and $\mathrm{V}$ phantoms, respectively. It can be seen that the lowest and the highest intensities are obtained with the crude and the $\mathrm{C} 2$ sample, respectively. The $\mathrm{C} 2$ sample produced signal intensities more than two times higher than those of Resovist ${ }^{\circledR}$. 
From the MPI parameter analysis as well as from the MPI phantom experiments it can, therefore, be concluded that the $\mathrm{C} 2$ (and to a lesser extent also the C3) formulation is a useful alternative for Resovist ${ }^{\circledR}$ and suitable contrast agent for MPI.

\section{Magnetic fluid hyperthermia}

Hyperthermia is a treatment modality in which cancerous tissue is exposed to a supernormal temperature. Cancer cells die as soon as temperatures exceed $42^{\circ} \mathrm{C}$, while normal cells can survive under these conditions [37]. Hyperthermia can be generated using radiofrequency, ultrasound and microwave energy, as well as using magnetic fluid hyperthermia (MFH). In MFH, increased temperatures are created by applying a sinusoidally alternating magnetic field (AMF). When SPION are exposed to an AMF, heat is generated to release the magnetic energy consumed for the alignment of the magnetization of the magnetic particles in the direction of the applied magnetic field. In principle, three mechanisms are responsible for heat dissipation, which can act separately or simultaneously, depending on the nanoparticle properties: (1) hysteresis power loss, originating from the irreversibility of the magnetization process, (2) Néel relaxation, conditioned by the rotation of the magnetic moments of the particles, and (3) friction losses due to Brownian rotation of the magnetic particles as a whole.
As a result of these three mechanisms, SPION and magnetic temperature gradually increase in an AFM until a saturation temperature is achieved [37, 38]. In a cellular environment, however, SPION are immobilized inside lysosomes and form agglomerates [39, 40]. This leads to partial blocking of the above-mentioned Brownian relaxation and to a drop in heating efficiency. In consequence, depending on the mechanism responsible for heat generation for a specific nanoparticle type, the in vivo hyperthermia performance could significantly decrease [30].

Figure $6 \mathrm{a}$ depicts the time-temperature curves for the monodisperse SPION batches $\mathrm{C} 1-\mathrm{C} 5$, as well as for the crude sample C, Resovist ${ }^{\circledR}$ and Sinerem ${ }^{\circledR}$ in a lowfrequency AMF. The iron concentration of all samples was $9 \mathrm{mM}$ and the dispersant media was DI water. For all size-isolated samples except for $\mathrm{C} 1$, the required time for increasing the temperature from 37 to $42{ }^{\circ} \mathrm{C}\left(\mathrm{t}_{\mathrm{H}}\right)$ was lower than for Resovist ${ }^{\circledR}$ and Sinerem ${ }^{\circledR}$. In this context, a shorter $t_{H}$ time reflects a better heating performance and contributes to shorter AMF application times in hyperthermia-based cancer treatment. The shortest $t_{H}$ value was achieved using C3, having a core size of $13 \mathrm{~nm}$. For this sample, the time to increase the temperature from 37 to $42{ }^{\circ} \mathrm{C}$ was $128 \mathrm{~s}$, which was approximately 3 times faster than for Resovist ${ }^{\circledR}\left(t_{H}=374 \mathrm{~s}\right)$.

In addition to $t_{H}$, the specific absorption rate $(\mathrm{SAR})$ is an important quantitative parameter to determine the
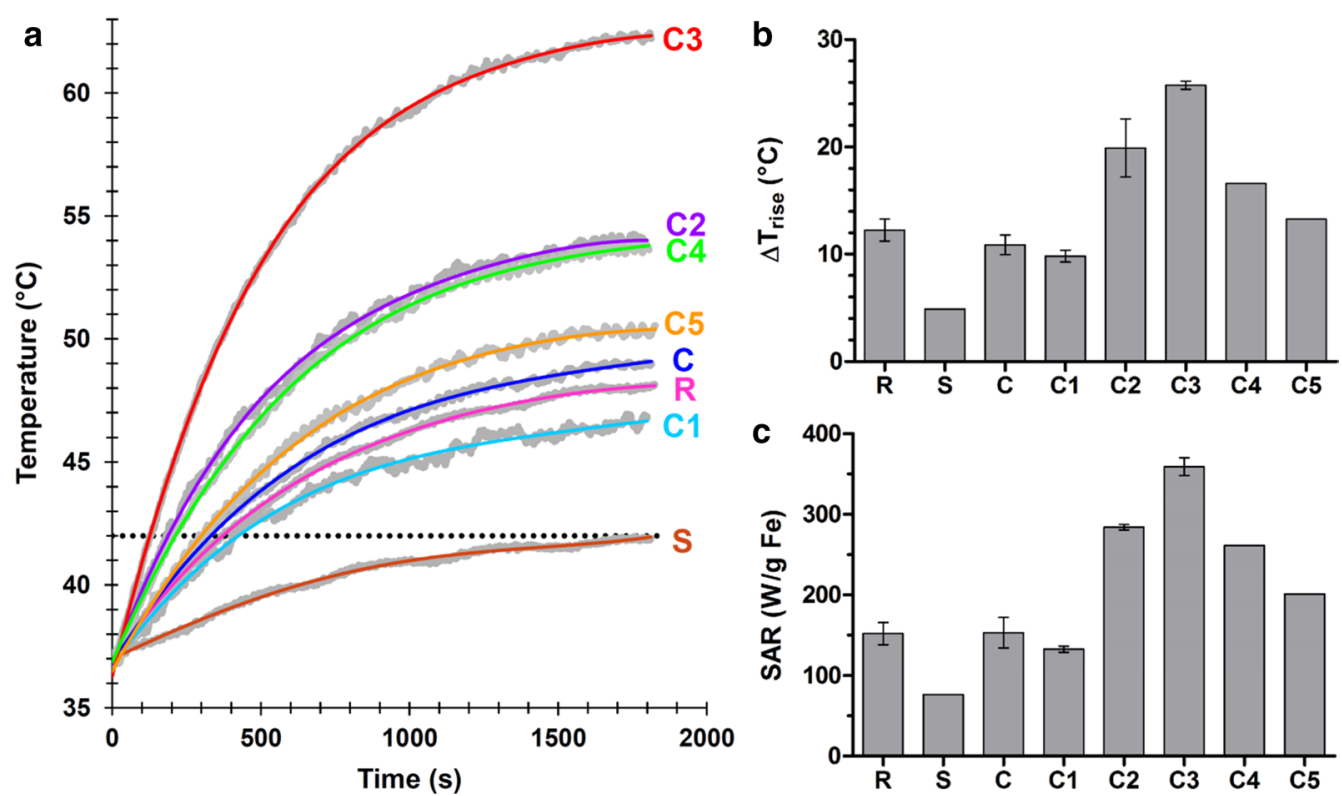

Fig. 6 Magnetic fluid hyperthermia using size-isolated SPION. a Time-temperature curves obtained upon exposing the crude, C1-C5, Resovist ${ }^{\circledR}$ and Sinerem ${ }^{\circledR}$ samples to an alternating magnetic field (AMF). The frequency and amplitude of the AMF were $186 \mathrm{kHz}$ and $46 \mathrm{kA} \mathrm{m}^{-1}$, respectively. The iron concentration was $9 \mathrm{mM}$ for all samples. A Box-Lucas curve was fitted to each data set. $\mathbf{b}$ Difference between initial and maximum temperatures after $30 \mathrm{~min}$ of field exposure $\left(\Delta \mathrm{T}_{\text {rise }}\right.$ ). c Specific absorption rate values (SAR; calculated on the basis of Additional file 1: Equations S5, S9). Values represent average \pm standard deviation of three separate experiments 
suitability of SPION formulations for MFH. From Additional file 1: Equations S7 and S8, it can be deduced that the SAR is directly proportional to $\Delta \mathrm{T}_{\text {rise }}$ which is defined as the difference between the maximum temperature reached during AMF exposure and the initial temperature (in this specific case $37^{\circ} \mathrm{C}$ ). Comparing the $\Delta \mathrm{T}_{\text {rise }}$ and the SAR values of the different formulations shows that the samples with a higher $\Delta \mathrm{T}_{\text {rise }}$ have a higher $\mathrm{SAR}$ and consequently a better MFH performance (Fig. 6b, c). For the C3 sample, the SAR was approximately 2.5 times higher than for Resovist ${ }^{\circledR}$. This indicates that the magnetic power absorbed per unit mass of the $\mathrm{C} 3$ sample in the presence of an AMF is $\sim 2.5$ times higher than that of Resovist ${ }^{\circledR}$. This high SAR value is expected to be due to a high saturation magnetization arising from individual magnetic anisotropy. Higher SAR values are beneficial from a clinical point of view, as they allow for lower SPION dosing to achieve similar hyperthermia efficacy.

A wide range of SAR values have been reported in the literature for diverse colloidal SPION formulations. SAR values strongly depended on the mean size and monodispersity of SPION, structural and magnetic properties, and the frequency and amplitude of the magnetic field. In the majority of cases, SAR values in the range between 4 and $100 \mathrm{~W} / \mathrm{g}$ were achieved for commercially available SPION dispersions [41]. For some customized formulations, higher SAR values have been reported. Bakoglidis and colleagues, for instance, synthesized spherical oleic acid-coated SPION with core sizes between 5 and $18 \mathrm{~nm}$ by thermal decomposition, and subjected them to MFH, showing maximal performance for $10 \mathrm{~nm}$, with a SAR of $230 \mathrm{~W} / \mathrm{g}$. They used hexane as the dispersion medium to maintain a stable suspension of the nanoparticles [42]. For the size-isolated C3 sample, we observed an SAR of $350 \mathrm{~W} / \mathrm{g}$, which exceeds this previously reported value by more than $50 \%$. This notion indicates that upon simple and straightforward size-isolation via sequential centrifugation, SPION formulations with optimal performance for biomedical applications can be readily obtained.

\section{Conclusion}

We here present a centrifugation protocol to obtain SPION with well-defined sizes (hydrodynamic diameter: $26.3 \pm 1.2, \quad 49.4 \pm 1.1, \quad 64.8 \pm 2.1, \quad 82.1 \pm 2.3$ and $114.6 \pm 4.4 \mathrm{~nm}$; and core size: $7.7 \pm 1.6,10.6 \pm 1.8$, $13.1 \pm 2.2,15.6 \pm 2.8$ and $17.2 \pm 2.1 \mathrm{~nm})$ and with a very narrow size distribution (PDI below 0.1) from a polydisperse starting mixture prepared via the co-precipitation technique. The samples obtained upon the 2nd and 3rd round of centrifugation, which had a core size of $10.6 \pm 1.8$ and $13.1 \pm 2.2 \mathrm{~nm}$, and a hydrodynamic diameter of $49.4 \pm 1.1$ and $64.8 \pm 2.1 \mathrm{~nm}$, were found to be optimal for MRI, MPI and MFH application, with an up to
3.3-, 3.3- and 7-fold improved performance as compared to the crude starting mixture, Resovist ${ }^{\circledR}$ and Sinerem ${ }^{\circledR}$, respectively. Our results demonstrate that simple and straightforward size-isolation helps to improve the performance for biomedical application.

\section{Experimental \\ SPION synthesis}

Eight mmol of ferric chloride was dissolved in DI water and mixed for 5 min under mechanical stirring. Subsequently, $4 \mathrm{mmol}$ of ferrous chloride tetrahydrate was added to the solution and mixed for a further $5 \mathrm{~min}$ at room temperature. The $\mathrm{pH}$ of the solution was adjusted to 11.0 by adding of $1 \mathrm{M}$ aqueous ammonia solution drop-wisely and it was stirred at $25{ }^{\circ} \mathrm{C}$ for $30 \mathrm{~min}$ under nitrogen atmospher. The formed black-colored iron oxide particles were decanted using a permanent magnet and washed at least three times with DI water. Afterwards, a specific amount of $0.1 \mathrm{M}$ hydrochloric acid was added to the particles and sonicated for $10 \mathrm{~min}$. Following, the citrate solution was added to the mixture and was stirred at $80^{\circ} \mathrm{C}$ for $2 \mathrm{~h}$. The citrate-coated polydisperse particles were separated by the use of a permanent magnet and then resuspended in DI water. Finally, the suspension was passed through a $0.2 \mu \mathrm{m}$ filter to remove the big particles. Additional synthetic details are provided in Additional file 1.

\section{SPION characterization}

The prepared SPION were subjected to several systematic analyses, to assess their properties and performance. The particle size and the size distribution of the crude sample, of the C1-C5 subfractions, and of Resovist ${ }^{\circledR}$ and Sinerem ${ }^{\circledR}$ were investigated by multiple different sizing techniques, including dynamic light scattering (DLS), nanoparticle tracking analysis (NTA) and transmission electron microscopy (TEM). The zeta potential values of the nanoparticles in aqueous solution were measured using a Zetasizer Nano-ZS (Malvern Instruments, Malvern, UK). The iron concentration of the respective samples was measured using the 1,10-phenanthroline assay [43]. We also evaluated the cytotoxicity of the samples. This was done via 2,3-bis-(2-methoxy-4-nitro5-sulfophenyl)-2H-tetrazolium-5-carboxanilide (XTT), lactate dehydrogenase (LDH) and reactive oxygen species (ROS) assays at multiple different iron concentrations, ranging from 0.1 to $10 \mathrm{mM}$. The colloidal stability of all size-isolated samples was investigated in two physiologically relevant media. These were fetal bovine serum (FBS), which is the most widely used serum-supplement for the in vitro cell culture, and bovine serum albumin (BSA). Colloidal stability was analyzed upon incubation in FBS and BSA for 2, 6 and $24 \mathrm{~h}$, via visual inspection 
and DLS analysis. Measurements of magnetic properties, including field-dependent magnetization, saturation magnetization $\left(\mathrm{M}_{\mathrm{s}}\right)$ and field-cooled (FC) magnetization, were performed using a Quantum MPMS-5XL SQUID magnetometer. Additional characterization details are provided in Additional file 1.

\section{SPION application}

MRI experiments were performed on a 3T clinical MR scanner (Philips Achieva, Best, The Netherlands) and images were acquired using SENSE-flex-M coil (Philips Achieva, Best, The Netherlands). From MRI tests, $R_{1}$ and $R_{2}$ relaxation rates and corresponding $r_{1}$ and $r_{2}$ relaxivities were calculated [44]. MPI measurements were performed using the Philips pre-clinical demonstrator system and relevant parameters of the SPION were determined including the signal-to-noise ratio (SNR) and the full width at half maximum (FWHM) of the point spread function (PSF). In order to evaluate hyperthermia performance, a custom-build setup (Trumpf Hüttinger, Freiburg, Germany) was employed and the heating efficiency of the different SPION formulations under an alternating magnetic field (AMF) was quantified using the specific absorption rate (SAR), which provides a measure of the magnetic power absorbed per unit mass of the magnetic material (see Additional file 1 for more details).

\section{Supplementary information}

Supplementary information accompanies this paper at https://doi. org/10.1186/s12951-020-0580-1.

\footnotetext{
Additional file 1: Figure S1. Zeta potential analysis of the crude, C1-C5, Resovist ${ }^{\circledR}$ and Sinerem ${ }^{\circledR}$ samples. Figure $\mathbf{S 2}$. Cell viability of $\mathrm{NIH} 3 \mathrm{~T} 3$ cells treated with the samples with various concentrations ofSPION for $4 \mathrm{~h}$ according to XTT assay. The data were normalized to control value (SPION-freemedia), which was set as 100\% cell viability. Experiments were performed at different concentrationsof SPION in the range of 0.1 to $10.0 \mathrm{mM}$. Values represent means \pm standard deviations of fiveidentical experiments made in three replicates. Figure S3. LDH leakage of NIH3T3 cells treated with the samples with various concentrations ofSPION for 4 $\mathrm{h}$ according to the manufacturer's instructions. Experiments were done at differentconcentrations of SPION in the range of 0.1 to $10.0 \mathrm{mM}$. Values represent mean \pm standard deviationof five identical experiments made in three replicates. Figure S4. ROS generated in NIH3T3 cells incubated with the samples with various concentrations ofSPION to the control cells (SPION-free media) after $24 \mathrm{~h}$ treatment. Experiments were done atdifferent concentrations of SPION in the range of 0.1 to $5 \mathrm{mM}$. Data represent mean \pm standarddeviation of three identical experiments made in three replicates. Figure S5. Colloidal stability of the samples in undiluted FBS monitored by visual inspection andDLS. Visual inspection indicated no aggregation up until $24 \mathrm{~h}$. In line with this, size and PDI obtainedby DLS also showed no significant changes at $24 \mathrm{~h}$. The iron concentration for all the samples was $5 \mathrm{mM}$. The FBS size according to DLS was $19.7 \pm 1.5$ $\mathrm{nm}$ which is very close to hydrodynamic diameterof C1. Also, FBS is polydisperse and has PDI of $0.49 \pm 0.05$. These two notions explain the high PDI forC1 in FBS. Figure S6. Colloidal stability of the samples in 4 $w t \%$ BSA in DI water. Visual inspection showed noaggregation at $24 \mathrm{~h}$. Also, size and PDI obtained by DLS showed no important differences in theirvalues at $24 \mathrm{~h}$. The iron concentration for all the samples was $5 \mathrm{mM}$.
}

Figure S7. Temperature-dependent magnetization at 1000 Oe of the crude SPION mixture $(C)$, thesize-isolated samples $C 1-C 5$, Resovist ${ }^{\circledR}(R)$ and Sinerem ${ }^{\circledR}(S)$. Results were normalized to Fe content. Figure S8. T1- and T2-weighted MR images of the crude, C1-C5, Resovist ${ }^{\circledR}$ and Sinerem ${ }^{\circledR}$ samples atdifferent concentrations from 0.005 to $0.05 \mathrm{mM}$. Figure $\mathbf{S 9}$. Longitudinal $(1 / \mathrm{T} 1 ; \mathrm{a})$ and transverse $(1 / \mathrm{T} 2 ; \mathrm{b})$ relaxation rates of the crude, C1-C5,Resovist ${ }^{\circledR}$ and Sinerem ${ }^{\circledR}$ samples as a function of concentration of Fe. The straight lines represent thelinear fit to the experimental data. The relaxivities $r 1$ and $r 2$ were calculated as the slope of the linesfitted to the experimental data. Values represent average of one experiment made in three replicates. Figure $\mathbf{S} 10$. Relaxivity ratios $\left(r_{2} / r_{1}\right)$ for the crude, C1-C5, Resovist ${ }^{\circledR}$ and Sinerem ${ }^{\circledR}$ samples. Figure S11. Normalized SNR values of the samples from the 4th up to the 10th harmonic of the MPIdrive field. Figure S12. Magnetic particle imaging of size-isolated SPION. (a) MPI images reconstructed basedon " $V$ " shaped phantoms filled with the crude sample, C2 and Resovist ${ }^{\circledR}$. (b) The intensity line profilesof the red marked lines through the phantoms in panel (a) are shown. The line profiles show the voxelintensity along the marked line and demonstrate a doubling of signal intensity for C2 in comparison toResovist ${ }^{\circledR}$. Table S1. Overview of the results obtained in the size analyses performed using TEM, DLS and NTA.The different SPION formulations were evaluated in different media and upon different storage times.

\section{Acknowledgements}

The authors acknowledge technical support by Marek Weiler.

\section{Authors' contributions}

SMD, FK and TL conceived the project. SMD, DC, MD, KR, PV, MS, NG, UE, MB and $J$ performed the experiments. JM, SB, IS, PK, BHS, VS, FK and TL supervised data collection and interpretation. SMD drafted the manuscript. All authors revised the manuscript. All authors read and approved the final manuscript.

\section{Funding}

The authors gratefully acknowledge financial support by the European Research Council (ERC: Starting Grant 309495 (NeoNaNo) and Proof-ofConcept Grants 680882 (CONQUEST) and 813086 (PIcelles), by the German Research Foundation (DFG: GRK2375 (grant 331065168), SFB/TRR57, SFB1066), and by RWTH Aachen University (ERS Prep Fund PFLS009).

\section{Availability of data and materials}

Data and materials will be made available upon request.

\section{Ethics approval and consent to participate}

We ensure adherence to relevant ethical standards.

\section{Consent for publication}

We agree to the publication policies of Journal of Nanobiotechnology.

\section{Competing interests}

The authors declare that they have no competing interests.

\section{Author details}

${ }^{1}$ Institute for Experimental Molecular Imaging, Faculty of Medicine, RWTH Aachen University, Forckenbeckstr. 55, 52074 Aachen, Germany. ${ }^{2}$ Department of Biomolecular Sciences, University of Urbino 'Carlo Bo', Via Aurelio Saffi 2, 61029 Urbino, Italy. ${ }^{3}$ Department of Scienze E Tecnologie Biologiche, Chimiche E Farmaceutiche (STEBICEF), University of Palermo, Palermo, Italy. ${ }^{4}$ Institute of Applied Medical Engineering, Helmholtz Institute, Faculty of Medicine, RWTH Aachen University, Pauwelsstrasse 20, 52074 Aachen, Germany. ${ }^{5}$ Electron Microscopy, Institute of Pathology, Faculty of Medicine, RWTH Aachen University, Pauwelstrasse 30, 52074 Aachen, Germany. ${ }^{6}$ Institute of Inorganic Chemistry, RWTH Aachen University, Landoltweg 1, 52056 Aachen, Germany. ${ }^{7}$ Department of Pharmaceutics, Utrecht University, Utrecht, The Netherlands. ${ }^{8}$ Department of Targeted Therapeutics, University of Twente, Enschede, The Netherlands.

Received: 19 June 2019 Accepted: 11 January 2020

Published online: 28 January 2020 


\section{References}

1. Dadfar SM, Roemhild K, Drude NI, von Stillfried S, Knüchel R, Kiessling F, Lammers T. Iron oxide nanoparticles: diagnostic, therapeutic and theranostic applications. Adv Drug Deliv Rev. 2019;138:302-25.

2. Gupta AK, Gupta M. Synthesis and surface engineering of iron oxide nanoparticles for biomedical applications. Biomaterials. 2005;26:3995-4021.

3. Laurent S, Forge D, Port M, Roch A, Robic C, Vander Elst L, Muller RN. Magnetic iron oxide nanoparticles: synthesis, stabilization, vectorization, physicochemical characterizations, and biological applications. Chem Rev. 2008;108:2064-110.

4. Lee N, Yoo D, Ling D, Cho MH, Hyeon T, Cheon J. Iron oxide based nanoparticles for multimodal imaging and magnetoresponsive therapy. Chem Rev. 2015:115:10637-89.

5. Wu W, Wu Z, Yu T, Jiang C, Kim W-S. Recent progress on magnetic iron oxide nanoparticles: synthesis, surface functional strategies and biomedical applications. Sci Technol Adv Mater. 2015;16:023501.

6. Ravikumar C, Bandyopadhyaya R. Mechanistic study on magnetite nanoparticle formation by thermal decomposition and coprecipitation routes. J Phys Chem C. 2011;115:1380-7.

7. Park J, An K, Hwang Y, Park J-G, Noh H-J, Kim J-Y, Park J-H, Hwang N-M, Hyeon T. Ultra-large-scale syntheses of monodisperse nanocrystals. Nat Mater. 2004:3:891.

8. Lemine O, Omri K, Iglesias M, Velasco V, Crespo P, De La Presa P, El Mir L, Bouzid H, Yousif A, Al-Hajry A. Y-Fe2O3 by sol-gel with large nanoparticles size for magnetic hyperthermia application. J Alloy Compd. 2014;607:125-31.

9. Okoli C, Sanchez-Dominguez M, Boutonnet M, Järås S. Civera Cn, Solans C, Kuttuva GR: Comparison and functionalization study of microemulsion-prepared magnetic iron oxide nanoparticles. Langmuir. 2012;28:8479-85.

10. Ozel F, Kockar H. Growth and characterizations of magnetic nanoparticles under hydrothermal conditions: Reaction time and temperature. J Magn Magn Mater. 2015;373:213-6.

11. Ramimoghadam D, Bagheri S, Hamid SBA. Progress in electrochemical synthesis of magnetic iron oxide nanoparticles. J Magn Magn Mater. 2014;368:207-29.

12. Stephens JR, Beveridge JS, Williams ME. Analytical methods for separating and isolating magnetic nanoparticles. Phys Chem Chem Phys. 2012;14:3280-9.

13. Guldris N, Argibay B, Kolen'ko YV, Carbó-Argibay E, Sobrino T, Campos F, Salonen LM, Bañobre-López M, Castillo J, Rivas J. Influence of the separation procedure on the properties of magnetic nanoparticles: gaining in vitro stability and T1-T2 magnetic resonance imaging performance. J Colloid Interface Sci. 2016:472:229-36.

14. Robertson JD, Rizzello L, Avila-Olias M, Gaitzsch J, Contini C, Magoń MS, Renshaw SA, Battaglia G. Purification of nanoparticles by size and shape. Scientific Rep. 2016;6:27494.

15. Paquet C, de Haan HW, Leek DM, Lin H-Y, Xiang B, Tian G, Kell A, Simard B. Clusters of superparamagnetic iron oxide nanoparticles encapsulated in a hydrogel: a particle architecture generating a synergistic enhancement of the T2 relaxation. ACS NanoNano. 2011:5:3104-12.

16. Fortin J-P, Wilhelm C, Servais J, Ménager C, Bacri J-C, Gazeau F. Size-sorted anionic iron oxide nanomagnets as colloidal mediators for magnetic hyperthermia. J Am Chem Soc. 2007;129:2628-35.

17. Beveridge JS, Stephens JR, Latham AH, Williams ME. Differential magnetic catch and release: analysis and separation of magnetic nanoparticles. Anal Chem. 2009;81:9618-24.

18. Moeser GD, Roach KA, Green WH, Hatton TA, Laibinis PE. High-gradient magnetic separation of coated magnetic nanoparticles. AIChE J. 2004:50:2835-48.

19. Singh N, Jenkins GJ, Asadi R, Doak SH. Potential toxicity of superparamagnetic iron oxide nanoparticles (SPION). Nano Rev. 2010;1:5358.

20. Mahmoudi M, Hofmann H, Rothen-Rutishauser B, Petri-Fink A. Assessing the in vitro and in vivo toxicity of superparamagnetic iron oxide nanoparticles. Chem Rev. 2011;112:2323-38.

21. Karlsson HL, Gustafsson J, Cronholm P, Möller L. Size-dependent toxicity of metal oxide particles-a comparison between nano-and micromete size. Toxicol Lett. 2009;188:112-8.

22. Yu S-M, Laromaine A, Roig A. Enhanced stability of superparamagnetic iron oxide nanoparticles in biological media using a pH adjusted-BSA adsorption protocol. J Nanopart Res. 2014;16:2484
23. Bañobre-López M, Teijeiro A, Rivas J. Magnetic nanoparticle-based hyperthermia for cancer treatment. Rep Pract Oncol Radiother. 2013:18:397-400

24. Kucheryavy P, He J, John VT, Maharjan P, Spinu L, Goloverda GZ, Kolesnichenko VL. Superparamagnetic iron oxide nanoparticles with variable size and an iron oxidation state as prospective imaging agents. Langmuir. 2013;29:710-6.

25. Hirt A, Kumari M, Heinke D, Kraupner A. enhanced methods to estimate the efficiency of magnetic nanoparticles in imaging. Molecules. 2017;22:2204

26. Du Y, Lai PT, Leung CH, Pong PW. Design of superparamagnetic nanoparticles for magnetic particle imaging (MPI). Int J Mol Sci. 2013;14:18682-710

27. Unni M, Uhl AM, Savliwala S, Savitzky BH, Dhavalikar R, Garraud N, Arnold DP, Kourkoutis LF, Andrew JS, Rinaldi C. Thermal decomposition synthesis of iron oxide nanoparticles with diminished magnetic dead layer by controlled addition of oxygen. ACS NanoNano. 2017;11:2284-303.

28. Kemp SJ, Ferguson RM, Khandhar AP, Krishnan KM. Monodisperse magnetite nanoparticles with nearly ideal saturation magnetization. RSC Adv. 2016:6:77452-64.

29. Baaziz W, Pichon BP, Fleutot S, Liu Y, Lefevre C, Greneche J-M, Toumi M, Mhiri T, Begin-Colin S. Magnetic iron oxide nanoparticles: reproducible tuning of the size and nanosized-dependent composition, defects, and spin canting. J Phys Chem C. 2014;118:3795-810.

30. Engelmann UM, Seifert J, Mues B, Roitsch S, Ménager C, Schmidt AM, Slabu I. Heating efficiency of magnetic nanoparticles decreases with gradual immobilization in hydrogels. J Magn Magn Mater. 2019;471:486-94

31. Lu Z, Deng R, Zhen M, Li X, Zou T, Zhou Y, Guan M, Zhang Y, Wang Y, Yu T. Size-tunable NaGdF 4 nanoparticles as $T 2$ contrast agents for high-field magnetic resonance imaging. RSC Adv. 2017;7:43125-31.

32. Saraswathy A, Nazeer SS, Jeevan M, Nimi N, Arumugam S, Harikrishnan VS, Varma PH, Jayasree RS. Citrate coated iron oxide nanoparticles with enhanced relaxivity for in vivo magnetic resonance imaging of liver fibrosis. Colloids Surf B. 2014;117:216-24.

33. Smolensky ED. Park H-YE, Zhou Y, Rolla GA, Marjańska M, Botta M, Pierre VC: Scaling laws at the nanosize: the effect of particle size and shape on the magnetism and relaxivity of iron oxide nanoparticle contrast agents. J Mater Chem B. 2013;1:2818-28.

34. Blanco-Andujar C, Walter A, Cotin G, Bordeianu C, Mertz D, Felder-Flesch D, Begin-Colin S. Design of iron oxide-based nanoparticles for MRI and magnetic hyperthermia. Nanomedicine. 2016;11:1889-910.

35. Schulz V, Straub M, Mahlke M, Hubertus S, Lammers T, Kiessling F. A field cancellation signal extraction method for magnetic particle imaging. IEEE Trans Magn. 2015;51:1-4.

36. Lindemann A, Lüdtke-Buzug K, Fräderich BM, Gräfe K, Pries R, Wollenberg B. Biological impact of superparamagnetic iron oxide nanoparticles for magnetic particle imaging of head and neck cancer cells. Int J Nanomed. 2014:9:5025.

37. Laurent S, Dutz S, Häfeli UO, Mahmoudi M. Magnetic fluid hyperthermia: focus on superparamagnetic iron oxide nanoparticles. Adv Coll Interface Sci. $2011 ; 166: 8-23$.

38. Thiesen B, Jordan A. Clinical applications of magnetic nanoparticles for hyperthermia. Int J Hyperth. 2008;24:467-74.

39. Engelmann UM, Roeth AA, Eberbeck D, Buhl EM, Neumann UP, SchmitzRode T, Slabu I. Combining bulk temperature and nanoheating enables advanced magnetic fluid hyperthermia efficacy on pancreatic tumor cells. Scientific Rep. 2018:8:13210.

40. Slabu I, Roeth AA, Engelmann UM, Wiekhorst F, Buhl EM, Neumann UP, Schmitz-Rode T. Modeling of magnetoliposome uptake in human pancreatic tumor cells in vitro. Nanotechnology. 2019;30:184004.

41. Kallumadil M, Tada M, Nakagawa T, Abe M, Southern P, Pankhurst QA. Suitability of commercial colloids for magnetic hyperthermia. J Magn Magn Mater. 2009;321:1509-13.

42. Bakoglidis K, Simeonidis K, Sakellari D, Stefanou G, Angelakeris M. Sizedependent mechanisms in $A C$ magnetic hyperthermia response of iron-oxide nanoparticles. IEEE Trans Magn. 2012;48:1320-3.

43. Kiwada H, Sato J, Yamada S. KATO Y: Feasibility of magnetic liposomes as a targeting device for drugs. Chem Pharm Bull. 1986;34:4253-8. 
44. Gremse F, Stärk M, Ehling J, Menzel JR, Lammers T, Kiessling F. Imalytics preclinical: interactive analysis of biomedical volume data. Theranostics. 2016;6:328.

\section{Publisher's Note}

Springer Nature remains neutral with regard to jurisdictional claims in published maps and institutional affiliations.
Ready to submit your research? Choose BMC and benefit from:

- fast, convenient online submission

- thorough peer review by experienced researchers in your field

- rapid publication on acceptance

- support for research data, including large and complex data types

- gold Open Access which fosters wider collaboration and increased citations

- maximum visibility for your research: over $100 \mathrm{M}$ website views per year

At BMC, research is always in progress.

Learn more biomedcentral.com/submissions 